Vol. XXVII No $2 \quad 2021$

\title{
THE ARCHITECTURAL DESIGN OF SUCCESSFUL ONLINE ENGLISH CLASSES
}

\author{
Daniela-Elena DURALIA \\ "Nicolae Bălcescu” Land Forces Academy, Sibiu, Romania \\ d_duralia@yahoo.com
}

\begin{abstract}
Various studies on the impact of online teaching and learning have shown the importance of a teacher's presence in the classroom, in terms of the efficiency of conveying knowledge. With online teaching, students show that they still require their teacher's involvement as well, demonstrating that his/her guidance and management of a class remains an important component of pedagogy. However, not all students decide to get equally involved in in-class activities, considering the issues that four groups of students in a university revealed during their online learning experience during the COVID-19 pandemic. Their need for better interaction with the teacher and their hesitancy to participate due to possible bullying, demonstrate that a teacher's presence is necessary. The PeerReview Approach and the Flipped Classroom Strategy were both helpful to the students as they were involved in activities under the teacher's observation. The latter could check the students' knowledge acquired before the start of the classes and monitor their learning process, which enhanced their feeling of self-confidence. As a result, the students could better concentrate and became more selfconfident as they succeeded academically.
\end{abstract}

\section{Keywords: Peer-Review, Covid-19, interaction, self-confidence}

\section{Introduction}

Over the last few decades, many effective ways of teaching second or foreign languages have widely been accepted, but progressively other newer teaching methods and approaches have been proven to be better. The teaching methods dating from 1970, such as the Total Physical Response, Suggestopedia, the Silent Way, and Counsel- Learning have been shadowed by the most recent approaches and methods that emerged as a result of recent research studies. A plethora of current teaching approaches, methods, and strategies, such as Problem-Based Learning, Inquiry-Based Learning, Game-Based Instruction, ProjectBased Instruction and Flipped Classroom, is to be taken into consideration,.
None of these teaching methods constitute a foolproof recipe for success. The outcomes of studies have emerged from the analysis of particular situations considering students' needs and background knowledge. The pedagogical material, the types of media and technology must always be chosen according to students' needs.

\section{Review of the Literature}

Various studies on the impact of online teaching and learning have revealed the importance of the teacher's presence as a guide and resource. Among them, Ellen Rose notes in her article "Faceless Teaching and Learning" that: "[students] are "these floating slightly tangential figures in the room or presences in the room that aren't 
full; I mean, they're not there.' Echoing the words of instructors, many students have told me that those with whom they interact in online courses don't 'feel real.' Interestingly, this feeling of disconnection appears to persist in synchronous courses. For example, one student told me that even interacting with classmates via synchronous video-streamed conversations is 'just not as personal [...] I don't know, I just don't feel as connected when I'm looking at somebody on the screen talking to me versus face-to-face. Face-to-face I feel like you pick up on things, there's just more of a feeling, more of an emotion." [1].

University students are tolerant and emotionally self-disciplined. As is most often the case, they are more mature and able to cope better with stressful situations. The current study in a university referring to online teaching reveals that students appreciate both ways of learning. On the one hand, face-to-face learning allows teachers to better understand when the information has been clearly transmitted, whereas online learning helps them better communicate among themselves. However, the teacher plays a role in ensuring a respectful environment conducive to learning.

Some students have lamented the overall lack of attention that teachers give to students with regards to the learning process results, such as whether a student has actually understood the topic under discussion. Another issue may also stem from the general lack of feedback given to students from their instructors. Natale and Libertella define empathy as "the ability to understand the world of others, to enter into that world and to experience what they are experiencing. As such is the condition sine qua non of meaning engagement. To engage others requires the capacity to be empathic" [2].

They also mention that "[...] in online encounter $[\ldots]$ important non-verbal and signaling behaviors are absent." Yet, "by developing more interactive scenarios, such as simulations, case work, and face-to-face synchronous discussions, online education is capable of approximating an engaged encounter. However, while it clearly lacks the vibrancy of face-to-face power-filled interactions, it does, however, both improve moral reasoning and prepare the way for moral and ethical encounter." [3]

Long-term online learning could become undesirable for students' social evolution since the environment becomes too rigid and inflexible. Natale and Libertella think that "The lack of face-to-face interaction is not just between student and teacher, but also amid classmates. [...] Much learning takes place between and among students outside the classroom, so this lacuna is problematic educationally." [4]

\section{The Study}

Online teaching has proven to be a new experience in many educational institutions. Both students and teachers had to adapt to new educational strategies and platforms. Some teachers felt frustrated because they did not have the same control as when they were teaching in the classroom. Besides, some would even blame students for their preference for such distancing. On the other hand, some students felt more relaxed indeed as they were not scrutinized every minute of the class and were not mocked anymore by their colleagues since they answered only when they felt confident. Such situations being given, the teacher's control proves the most needed.

The teacher's empathy will always be the most powerful instrument in the setting of the directions leading to the achievement of the learning objectives. Understanding students' needs and perspectives can highly contribute to the forming of the lesson plan. Therefore, a clear presentation of the learning objectives can lead to the planning of a successful teaching approach. During either online or face-to-face teaching, a well-planned lesson can contribute to students' involvement during the class. Garrison, Anderson \& Archer note that 
„Cognitive presence is the extent to which learners are able to construct and confirm meaning through sustained reflection and discourse" [5].

The Peer-Review approach enables students to interact with each other on study topics leaving no space for bullying. Students cannot afford to lack respect for each other. Such practice of expressing one's opinion about one's peer's work demands that students engage in in-class discussion. Those who are cognitively involved in activities bring with them a strong contribution to the lesson, which could help to develop some of their ideas or rather clear up some of the confusion for their peers. The teacher's role comes down to guiding, organizing, and stimulating students, all of which contribute to making the learning process as dynamic as possible. Students in a first-class university group could hardly express themselves in the classroom during the first semester. Having switched to online classes during the second semester, they noticed a tendency to avoid expressing their opinion because they felt intimidated by their classmates. The online experience and the discussion about this embarrassment helped them overcome the stress they had. In this situation, the Flipped Classroom strategy proved efficient reminding of Hereid \& Schiller's observation that: "the real learning happens, not when the teacher is lecturing, droning on and on. The flipped classroom, with its use of videos that engage and focus student learning, offers us a new model for case study teaching, combining active, studentcentered learning with content mastery that can be applied to solving real-world problems. It's a win-win" [6].

Teachers' requirement of students' covering sections of theory before they came to the class also contributed to students' reduction of tension and increase of self-confidence. They would more often provide answers to the teachers' questions, being sure that the answers were correct. They felt no danger of being shamed or judged. Students went on to build up their repertoire of knowledge by actively engaging in the activities organized by the teacher. The result was the students' overall improvement in their academic work.

\section{Conclusion}

The development of communicative competencies proved to be an overarching strategy in the learning process. With online learning, the teacher had to structure the material of the course visible on the Moodle platform, which could better help students visualize the goal of the course. Not all teachers use the blackboard or the overhead projector as part of their teaching equipment. In this study, the students could benefit from activities and PowerPoint lectures. The distance imposed on them by this way of teaching prompted students to adopt different attitudes that could help them regain their self-confidence in their work and express themselves freely, without fear of ridicule.

On the other hand, some showed regret for the lack of face-to-face interaction with the teacher. During the online learning, the Peer-Review approach represented a bridge for students to learn to respect each other, reaching a cognitive zone of interaction where they could exchange their views. (Figure 1)

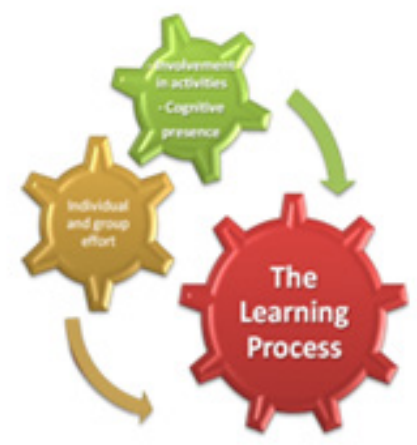

Figure 1: The Peer Review Approach

Even if online learning is beneficial for students during the class, the learning process cannot limit itself to the use of a platform being of great use for practice. 
Discipline, students' needs, and the explanation necessary at different instances during the class are most often neglected when just working on the platform. The Peer-Review approach and the Flipped Classroom strategy involve all students whose interaction and maximum contribution offer the picture containing all imperfections to be taken care of by the teacher. (Figure 2)

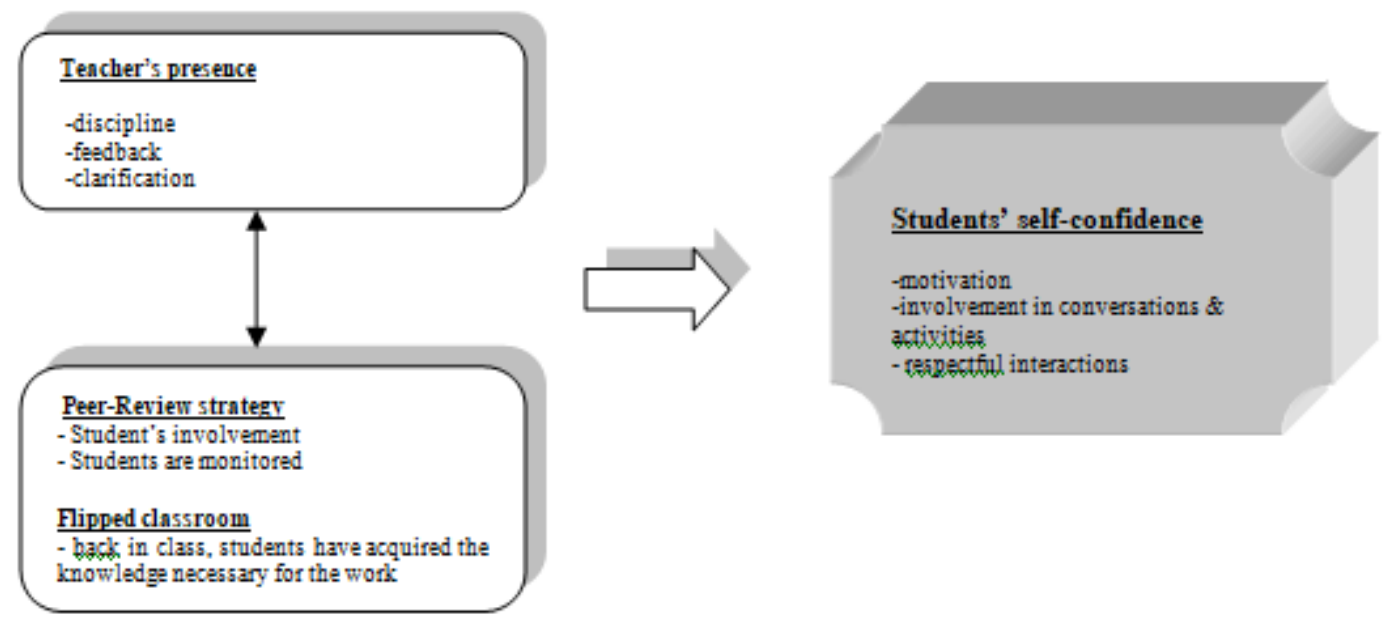

Figure 2: Online teaching applying the Peer-Review Approach and the Flipped Classroom

\section{References List}

[1] Rose Ellen. Faceless Teaching and Learning. Educational Technology Publications, Inc. January-February 2016, Vol. 56, No. 1 (January February 2016), p. 59.

[2] Natale, S.M. and Libertella, A.F. Values Dilemma in Business and the Search for Empathic Engagement. Springer. Journal of Business Ethics, September 2016, Vol. 138, No. 1 (September 2016), p. 177.

[3] Idem, p. 177

[4] Idem, p. 179

[5] https://coi.athabascau.ca/coi-model/

[6] Herreid, C. F. and Nancy A. Schiller. Case Studies and the Flipped Classroom. Journal of College Science Teaching, National Science Teachers Association, May/June 2013, Vol. 42, No. 5 (May/June 2013), p. 65. 